\title{
Xenogenic Gama-irradiated Pathogen Harbouring Macrophage Based Vaccine: Prophylactic Potential against Intracellular Pathogen C. neoformans
}

\author{
Chauhan $\mathrm{A}^{1^{*}}$, Khan $\mathrm{N}^{1}$, Pooja $\mathrm{C}^{1}$, Khan $\mathrm{AA}^{2}$, Swaleha $\mathrm{Z}^{3}$, Mohammad $\mathrm{O}^{4}$ and Abida $\mathbf{M}^{5}$ \\ ${ }^{1}$ School of Medicine and Health Sciences, University of North Dakota Grand Forks 58203, USA \\ ${ }^{2}$ Department of Pharmaceutical Chemistry, College of Pharmacy, King Saud University, Riyadh, Saudi Arabia \\ ${ }^{3}$ Women's College, Aligarh Muslim University, Aligarh-202002, India \\ ${ }^{4}$ Interdisciplinary Biotechnology Unit, Aligarh Muslim University, Aligarh-202002, India \\ ${ }^{5}$ Department of Microbiology, J. N. Medical College, Aligarh Muslim University, Aligarh-202002, India
}

*Corresponding author: Chauhan A, School of Medicine and Health Sciences, University of North Dakota, Grand Forks ND 58203. USA, E-mail: arun.chauhan@med.und.edu

Received date: February 27, 2016; Accepted date: March 29, 2016; Published date: April 01, 2016

Copyright: @ 2016 Chauhan A, et al. This is an open-access article distributed under the terms of the Creative Commons Attribution License, which permits unrestricted use, distribution, and reproduction in any medium, provided the original author and source are credited.

\begin{abstract}
The lack of early and effective diagnostic procedure, toxicity displayed by the most commonly used fungicidal drugs and emergence of resistant strains responsible for high morbidity and mortality requires an urgent need for vaccination against intracellular pathogens. In the present study, we report the use of $y$-irradiated pathogen primed macrophages as an immuneprotective agent against disseminated cryptococcosis. The T-cell proliferation analysis clearly showed that the $\gamma$-irradiated pathogen primed macrophages proved to be a better immunestimulatory agent than the cytosolic fraction of $C$. neoformans. Mice immunized with different vaccine formulations developed CD8 ${ }^{+} \mathrm{T}-$ cell mediated Th-1 response as was assessed from the cytokine profiling and IgG isotyping. Protective studies in immunized animals challenged with live $C$. neoformans showed improved survival rates. However, the protective efficacy was highest in case of animals immunized with xenovaccines as was evaluated with increased survival rate $(80 \%)$ and decreased fungal burden in the vital organs of the animals compared with control groups and groups of mice immunized with allovaccines or for that matter synvaccines. Together, these suggest that $\gamma$-irradiated pathogen harboring xenovaccines could play an active role in imparting protection against experimentally disseminated Cryptococci infection.
\end{abstract}

\section{Introduction}

Fungi are associated with wide spectrum of diseases in humans and animals, ranging from benign colonization and allergy to life threatening diseases and autoimmunity. A variety of underlying conditions; including impaired immune status, use of immunosuppressive drugs etc. are believed to account for the susceptibility to fungal infections [1-3] and to determine both the severity and characteristics of the associated pathology. Similar to Candida albicans and Aspergillus fumigates, Cryptococcus neoformans, environmental encapsulated pathogenic yeast causes lifethreatening infections in immunocompromised as well as immunocompetent hosts [4-7]. C. neoformans has a particular fondness for brain in addition to a little for lungs, bones and skin [8]. Once the desiccated yeast cells or spores are inhaled, the lung provides niches for their intracellular and extracellular growth [9]. Hence, $C$. neoformans is a facultative intracellular pathogen. Because of precise predilection for central nervous system, fungal cells if uncontrolled can travel to brain causing meningoencephalitis that may result in fatality.

C. neoformans being a facultative intracellular pathogen can replicate within macrophages [10,11], specifically within their phagolysosomes [12,13]. Thus, although development of cryptococcosis is due to both intra- and extracellular $C$. neoformans growth [14-15], it is reasonable to hypothesize that in conditions in which there is immunodeficiency, the intracellular component could aggravate cryptococcosis. This hypothesis is derived from the following observations: (i) C. neoformans can replicate faster intracellularly than extracellularly [15]; (ii) $C$. neoformans can disseminate within macrophages $[19,20]$; and (iii) live $C$. neoformans cells can escape from macrophages without killing the host cells [21,22]. Therefore, if upon phagocytosis macrophages cannot effectively kill $C$. neoformans, phagocytosis can be considered as an opportunity for the fungus to produce disease. Thus, prophylaxis against intracellular mode of fungal growth can help to control the disease.

The macrophages gather antigens from the local environment but are not in an immune-stimulatory state. It has been documented that antigen presenting cells (APCs) are endowed with pattern recognition receptors that recognize unique features of microbial molecules called pathogen associated molecular patterns [23-25]. When PAMPs are present from an infection or adjuvant, then they are stimulated to migrate to the lymphoid tissues and present both the antigen and costimulatory molecules (CD80 and CD86) to the T-cells.

In another model it has been documented that crucial event controlling the initiation of an immune response is not infection, but the production of danger signals known as damage associated molecular patterns (DAMPs) from the cells stressed, damaged and/or dying in the local tissues [26]. These were postulated to act on the APCs in a manner that also caused them to migrate to the local tissues and present antigens to the T- cells in an immune-stimulatory manner. It has been speculated that PAMS and DAMPS may act independently or even synergistically eventually causing the activation of the immune system. It is this that prompted us to use $\gamma$ irradiated pathogen primed 
Citation: Chauhan A, Khan N, Pooja C, Khan AA, Swaleha Z, et al. (2016) Xenogenic Gama-irradiated Pathogen Harbouring Macrophage Based Vaccine: Prophylactic Potential against Intracellular Pathogen C. neoformans. J Vaccines Vaccin 7: 316. doi: $10.4172 / 2157-7560.1000316$

Page 2 of 8

macrophages as novel candidate for vaccine development against intracellular pathogens.

\section{Materials and Methods}

\section{Materials}

The P815 cells, EL-4 cell lines of macrophages used in the study were obtained from ATCC (Rockville, MD). THP-1 was provided by Dr. Dubey (Central Drug Research Institute, Lucknow). Fetal calf serum (FCS) was purchased from Harlan Sera Lab, and RPMI 1640 medium was purchased from GIBCO. Antibodies to IL-2, IL-4 and IFN- $\gamma$ were obtained from Pharmingen. Biotinylated goat anti-mouse IgG1 and IgG2a were procured from Sigma Chemicals, and Streptavidin linked anti-goat horseradish peroxidase was also purchased from Sigma chemical company. $\left[\mathrm{H}^{3}\right]$ Thymidine and $\left[{ }^{51} \mathrm{Cr}\right]$ sodium chromate were procured from Bhabha Atomic Research Center.

\section{Culture of fungal cells}

Cryptococus neoformans was grown on YPD-agar plates and incubated overnight at $37^{\circ} \mathrm{C}$. Thereafter yeast cells were enumerated by hemocytometer.

\section{Co-culturing of fungal cells with macrophages and vaccine preparation}

The cells were cultured and maintained in HEPES buffered RPMI 1640 medium supplemented with FCS (10\%), sodium bicarbonate (2\%) and antibiotic/ antimycotic solutions (Sigma). The plated cells were maintained overnight at $37^{\circ} \mathrm{C}$ in $5 \% \mathrm{CO}_{2}$. THP-1 cells were activated with PMA $(50 \mathrm{ng} / \mathrm{ml})$ for $20 \mathrm{hrs}$. The monolayer of cells were then infected with live Cryptococcus neoformans at an MOI of 20 yeast/ macrophage for $1 \mathrm{~h}$, which was followed by extensive washing with RPMI 1640 medium to remove extracellular fungi. The cells were treated with Amp B (50 mg/ml) for $49 \mathrm{~h}$ to kill residual extracellular fungi and with fluconazole $(100 \mathrm{mg} / \mathrm{ml})$ for $48 \mathrm{~h}$ to kill intracellular yeast. The cells were harvested and gamma irradiated with a dose of 1.6 $\mathrm{kGy}$. The vaccine preparation was washed and resuspended at a concentration of $5 \times 10^{6}$ cells $/ \mathrm{ml}$ in PBS. There were usually 2-5 yeast/ macrophage, as observed by fluorescence microscopy using antisurface antibodies for yeast. The vaccines were checked for the growth of $C$. neoformans by plating $100 \mathrm{ml}$ of cell suspension in YPD agar after diluting it 1:1 with normal saline. No fungal growth was observed.

\section{Preparation of whole cell lysates of macrophages}

The balb/c mice were infected with live $C$. neoformans. three days post infection, the macrophages derived from the peritoneal cavity were lysed in $100 \mathrm{ml}$ of ice-cold lysis buffer $(10 \mathrm{mmol} / \mathrm{L}$, Tris [pH 8.0], $1 \%$ Triton X-100, $150 \mathrm{mmol} / \mathrm{L} \mathrm{NaCl}, 5 \mathrm{mmol} / \mathrm{L}$ EDTA, $1 \mathrm{mmol} / \mathrm{L}$ phenylmethanesulfonyl fluoride, $10 \mathrm{mg} / \mathrm{l}$ aprotinin, and $10 \mathrm{mg} / \mathrm{L}$ leupeptin). Disrupted cells were centrifuged at $600 \mathrm{~g}$ for $20 \mathrm{~min}$. the supernatant was further fractionated by ultracentrifugation at 100,000 $\mathrm{g}$ for $1 \mathrm{~h}$ at $4^{\circ} \mathrm{C}$, and pellet, rich in cellular membranes was discarded. The supernatant was then subjected to extensive dialysis against PBS and was concentrated by use of Amicon filters. The protein concentration was determined by Bicinchoninic Acid method.

\section{Isolation of cytosolic fraction from fungal cells}

C. neoformans was cultured on YPD agar plates. The cells were harvested after $24 \mathrm{~h}$ and homogenized in chilled lysis buffer ( $2 \%$ Triton $\mathrm{X}-100$ (w/v), $1 \%$ SDS, $100 \mathrm{mM}$ Tris- $\mathrm{HCl}$ (pH 8.0), 100mM NaCl, $1 \mathrm{mM}$ EDTA, 1mM PMSF). The homogenate was sonicated for 45 mins at $4^{\circ} \mathrm{C}$. After sonication the homogenate was vortexed for $1 \mathrm{~h}$ by intermittent cooling to $4^{\circ} \mathrm{C}$. The preparation was pelleted at $2000 \mathrm{~g}$ for 15 mins and the supernatant was collected. The concentration of protein was determined by Bicinchoninic Acid method.

\section{Immunization of mice with vaccine}

Different groups of mice were immunized intraperitoneally with different preparation of vaccine (i.e. $5 \times 10^{5}$ infected macrophages in $100 \mu \mathrm{l}$ of $\mathrm{PBS} / \mathrm{mouse})$. One group of mice was inoculated with allovaccine (i.e. $C$. neoformans cultured in allogenic EL-4 macrophages), the second group was inoculated with synvaccine (i.e. C. neoformans cultured in syngeneic P815 macrophages), and the third group was inoculated with xenovaccine (i.e. $C$. neoformans cultured in xenogeneic THP-1 derived macrophages). Ten days after the primary immunization, the mice received primary booster with the same preparation. Seven days after the second booster vaccination, all the groups were immunized with synvaccine. The control group of mice was immunized with $100 \mu \mathrm{l}$ of PBS or killed yeast cells.

\section{Lymphocyte proliferation assay}

Seven days after the final booster the mice were killed and the lymphocytes obtained from the spleen of the sacrificed animals. Lymphocytes isolated from the spleen of the mice immunized intraperitoneally with different vaccine preparation were cultured in flat-bottomed 96-well micro titer plates, with $2 \times 10^{5}$ cells/well in 200 ml HEPES buffered RPMI-1640 medium supplemented with 10\% FCS. Each well also contained $1 \times 10^{6}$ thioglycolate activated macrophage. The cultures were stimulated with different concentration (1.0-500 $\mu \mathrm{g} / \mathrm{ml}$ ) of whole cell lysates that were generated by infecting syngeneic peritoneal macrophage with live $C$. neoformans. Lymphocytes stimulated with PBS alone and killed yeast cells were used as a control. After $72 \mathrm{~h}$, the cultures were pulsed with $0.5 \mu \mathrm{Ci}$ of $\left[{ }^{3} \mathrm{H}\right]$-Thymidine (Bhaba Atomic Research Center). The plates were harvested after $16 \mathrm{~h}$ onto glass-fiber filters by use of a skatron cell harvester (Skatron) and were counted by use of liquid scintillation spectroscopy (LKB Wallac LS 1800; Beckman Instruments). A similar experiment was set up where by the cultured cells were stimulated with different concentration $(1.0-100 \mu \mathrm{g} / \mathrm{ml})$ of infected cell lysates. The proliferation of T-cells was quantified in a similar manner as described above. The results in both cases were then compared.

\section{$\left[{ }^{51} \mathrm{Cr}\right]$ release assay}

The $\left[{ }^{51} \mathrm{Cr}\right]$-labelled macrophages/P815 cells $\left(5 \times 10^{3} /\right.$ well $)$ were used as target cells. The antigen primed target cells were incubated with $\mathrm{CD}^{+} \mathrm{T}$ cells (effector cells isolated from the spleen of 8 to 10 mice were pooled, and used for assay) at an effector to target $(\mathrm{E} / \mathrm{T})$ ratios of 25:1. The cells were incubated at $37^{\circ} \mathrm{C}$ for $6 \mathrm{hrs}$, after completion of incubated periods, the cells were pelleted at $3000 \mathrm{~g}$ for $15 \mathrm{~min}$ at $5^{\circ} \mathrm{C}$ and the amount of $\left[{ }^{51} \mathrm{Cr}\right]$ released was determined by measuring the radioactivity in the supernatant. The spontaneous release if $\left[{ }^{51} \mathrm{Cr}\right]$ in the supernatant was determined by incubating the labeled macrophages for $6 \mathrm{hrs}$. Amount of auto-release was subtracted from the total release to determine the extent of macrophage lysis. In most of 
Citation: Chauhan A, Khan N, Pooja C, Khan AA, Swaleha Z, et al. (2016) Xenogenic Gama-irradiated Pathogen Harbouring Macrophage Based Vaccine: Prophylactic Potential against Intracellular Pathogen C. neoformans. J Vaccines Vaccin 7: 316. doi: $10.4172 / 2157-7560.1000316$

Page 3 of 8

the experiments, the auto-release was less than $25 \%$. The percent specific release was calculated as the (mean sample cpm-mean spontaneous $\mathrm{cpm}) /($ mean maximum cpm-mean spontaneous $\mathrm{cpm}) \times$ $100 \%$.

\section{Lymphokine assay}

The cultures were set as described in the $\mathrm{T}$ cell proliferation. The supernatant from the experiment and control cultures were harvested after $24 \mathrm{~h}$ and $48 \mathrm{~h}$ for IFN- $\gamma$, IL-2, IL-4 and IL-12 and their concentration determined by sandwich ELISA method.

\section{IgG Isotyping assay}

The sera obtained after each booster were analyzed for IgG1 and IgG2a isotype by ELISA. Triplicate wells were coated with $100 \mu$ of cell lysates in carbonate-bicarbonate buffer $(\mathrm{pH}$ 9.6) were incubated for a period of 2 hrs. The unbound sites were blocked with $5 \%$ skimmed milk and incubated overnight at $4^{\circ} \mathrm{C}$. There after 1:500 dilutions of serum were added and the plate incubated at $37^{\circ} \mathrm{C}$ for a period of $2 \mathrm{~h}$. IgG1 and IgG2a was detected using $50 \mu \mathrm{l}$ biotinylated goat anti-mouse igG1 and IgG2a antibody respectively. After incubating the plates at $37^{\circ} \mathrm{C}$ for $1 \mathrm{~h} 50 \mu \mathrm{l}$ of streptavidin-HRP was added. The usual method of washing using PBS-Tween 20 was carried out at each step. Colour developed using OPD (ortho-phenyelene diamine) was visualized at $492 \mathrm{~nm}$. Antibody titters are expressed as the highest dilution of the serum that yielded an OD of 0.2 above the control wells (i.e. serum obtained from the animals immunized with PBS). harvested as described earlier, $1 \times 10^{6}$ splenocytes were taken into centrifuge tubes and washed twice into FACS buffer (PBS with $1 \%$ BSA and $0.1 \%$ sodium azide), then required concentration (125 ng for $1 \times$ $10^{6}$ cells) of FITC/PE tagged anti CD80 and CD86 were incubated into corresponding tubes for 1 hour, after that washing was done twice, then cells were fixed in $1 \%$ paraformaldehyde. Tagged cells were counted using express plus software provided by manufacturer. FITClabelled isotypic antibody was used as the control.

\section{Protection studies}

Fungal load in the spleen and kidney were studied by plating colony-forming units. Seven groups of mice/group were subjected to different vaccination protocols, as described above. Seven days after the final booster vaccination, all groups were challenged with $5 \times 10^{6}$ viable yeast of $C$. neoformans/mouse. Mice were killed on various days after challenge. Numbers of viable $C$. neoformans (colony forming units) in the spleen were enumerated by plating serial 10 -fold dilutions of spleen homogenates using NCCLS recommended method. The data are expressed as the $\log 10$ value of the mean number of yeast recovered per spleen.

\section{Results}

\section{Lymphocyte proliferation assay}

The macrophage based vaccines were evaluated for their ability to induce clonal proliferation of T-lymphocytes in vitro.

\section{FACS}

Different surface markers of macrophages were evaluated by using fluorescence activated cell sorter (GAVAVA), the splenocytes were
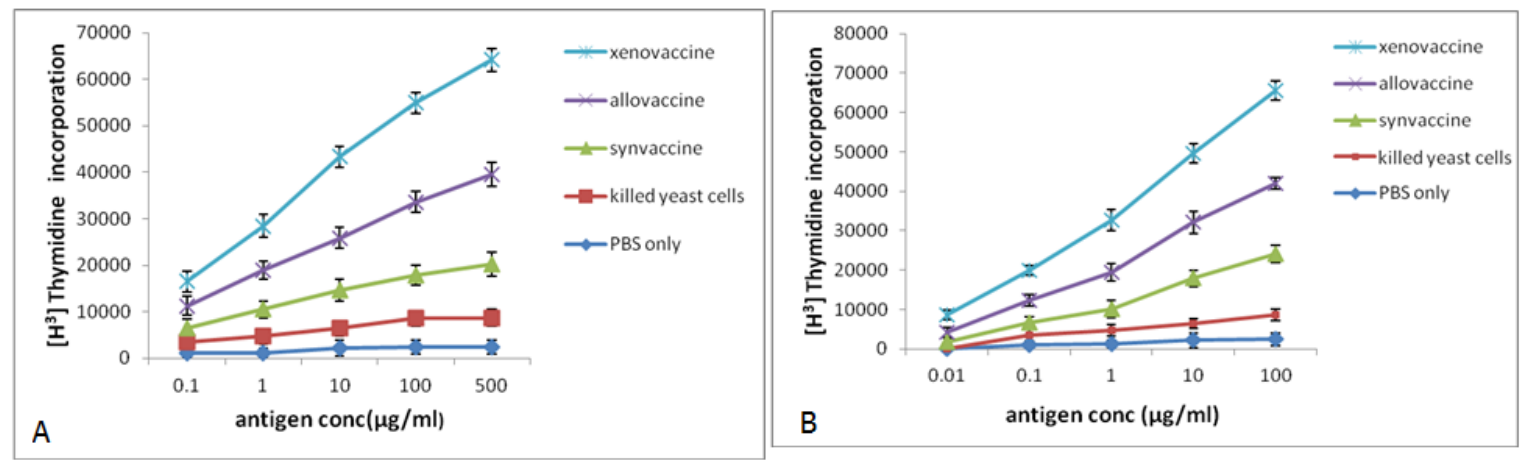

Figure 1: A) Analysis of T-cell proliferation in mice immunized with various forms of $C$. neoformans total cell lysate. T-cells were obtained from spleen of mice immunized with different vaccines formulations. The spleen $\mathrm{T}$ cells were stimulated with a mixture of cAg with different Conc. $(0.001-500 \mu \mathrm{g} / \mathrm{ml})$. After $72 \mathrm{hr}$ cultivation, the proliferation of T-cells was determined by [3H]-thymidine incorporation. [H3] Thymidine incorporation was measured using liquid scintillation counter. Cells primed with PBS alone and killed yeast cells served as the control. Each point in the graph represents three determinations \pm S.D. B) Analysis of T-cell proliferation in mice immunized with different forms of vaccine in response to whole cell lysate of macrophages infected with live $C$. neoformans. T-cells were obtained from spleen of mice immunized with different vaccines formulations. The spleen T cells were stimulated with a mixture of cAg with different Conc. $(0.001-100 \mu \mathrm{g} /$ $\mathrm{ml}$ ). After $72 \mathrm{hr}$ cultivation, the proliferation of T cells was determined by $\left[{ }^{3} \mathrm{H}\right]$-thymidine incorporation. [H3] Thymidine incorporation was measured using liquid scintillation counter. Cells primed with PBS alone and killed yeast cells served as the control. Each point in the graph represents three determinations \pm S.D.

As shown in Figure 1, the macrophage incorporated antigen/ pathogen activated host immune system. T-cell proliferation was found to be more prominent in case of whole cell lysate of macrophages infected with live $C$. neoformans. Proliferation was found to be 
Citation: Chauhan A, Khan N, Pooja C, Khan AA, Swaleha Z, et al. (2016) Xenogenic Gama-irradiated Pathogen Harbouring Macrophage Based Vaccine: Prophylactic Potential against Intracellular Pathogen C. neoformans. J Vaccines Vaccin 7: 316. doi: $10.4172 / 2157-7560.1000316$

Page 4 of 8

maximum in case of mice immunized with xenovaccine followed by allovaccine and minimum T-cell activation was observed in the group of animals immunized with synvaccine. Incubation with $C$. neoformans whole cell lysate also showed $\mathrm{T}$ cell proliferation in a dose dependent manner (Figure 1A) though it required a higher concentration $(500 \mu \mathrm{g} / \mathrm{ml})$ of the antigen whereas same degree of T-cell proliferation was observed (Figure 1B) upon incubation with 100 $\mu \mathrm{g} / \mathrm{ml}$ whole cell lysate of macrophages infected with live $C$. neoformans.

\section{${ }^{51} \mathrm{Cr}$ release assay}

The lysis of the target cells was measured by ${ }^{51} \mathrm{Cr}$ release assay (Figure 2). Interestingly, immunization with xenovaccine, allovaccine and synvaccine but not various empty macrophages (sham P815, sham EL-4 and sham THP-1) and killed yeast cells generated cytotoxic T cells. A considerably high degree (50-60\%) of target cell lysis occurred when the animals were immunized with xenovaccine followed by allovaccine and synvaccine that resulted in $30-40 \%$ and $10-20 \%$ lysis of target cells respectively. Empty macrophages and killed yeast cells exhibited less than $1 \%$ specific lysis.

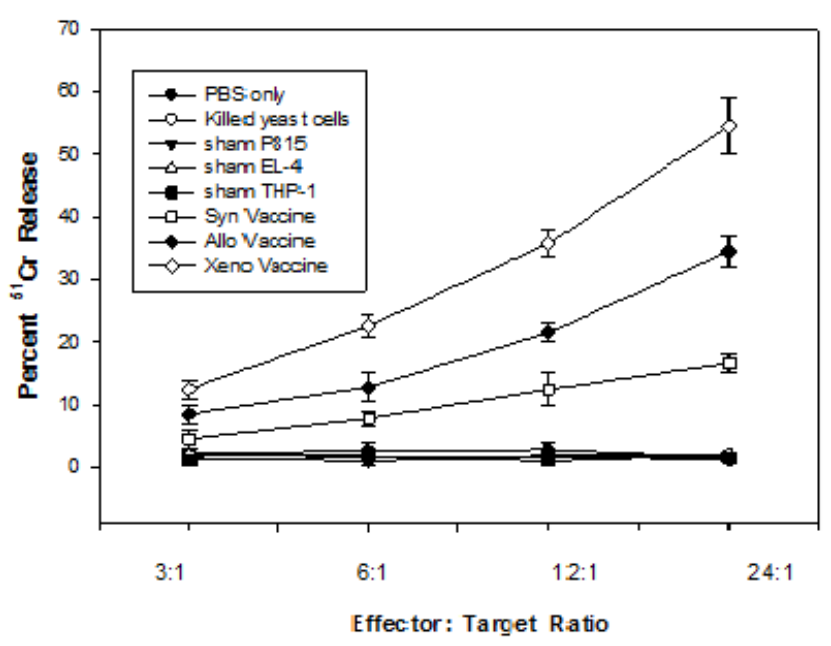

Figure 2: Analysis of $\left[{ }^{51} \mathrm{Cr}\right]$ release assay in mice immunized with various forms of vaccine in response to whole cell lysate of macrophages infected with live C. neoformans. The $\left[{ }^{51} \mathrm{Cr}\right]$-labeled macrophages/P815 cells $\left(5 \times 10^{3} /\right.$ well $)$ were used as target cells. The antigen primed target cells were incubated with $\mathrm{CD} 8^{+} \mathrm{T}$ cells (effector cells isolated from the spleen of 8 to 10 mice were pooled, and used for assay) at an effector to target (E/T) ratios of 25:1. ${ }^{\left[{ }^{51} \mathrm{Cr}\right]}$ release was determined at different effector: target ratio. Cells primed with PBS alone and killed yeast cells were used as control. Each point in the graph represents three determinations \pm S.D.

\section{Upregulated expression of type I cytokines by immunizing the animals with different forms of vaccine}

From the cytokine profiling shown in Figure 3, it is clear that mice immunized with different forms of macrophage based vaccine when primed with the whole cell lysate of macrophages infected with $C$. neoformans show an increase in the level of IFN- $\gamma$, IL-2 whereas there is a decrease in the concentration of IL-4. In contrast control groups involving immunization with dead fungal cells yielded mainly type II cytokines (data not shown). Sera isolated on the $7^{\text {th }}$ day postsecondary booster were used for carrying out the cytokine profiling for IL-12. The level of IL-12 was also found to increase as is evident from figure 2 . This clearly supports the above mentioned data as it is IL-12 that regulates the release of IFN- $\gamma$. Among the three preparations, syngenic vaccines were found to generate both type I and type II cytokines while allogenic and xenogeneic vaccines induced type I cytokines mainly. Control groups consisting of sham (empty) macrophages were found to induce insignificant release of cytokines.

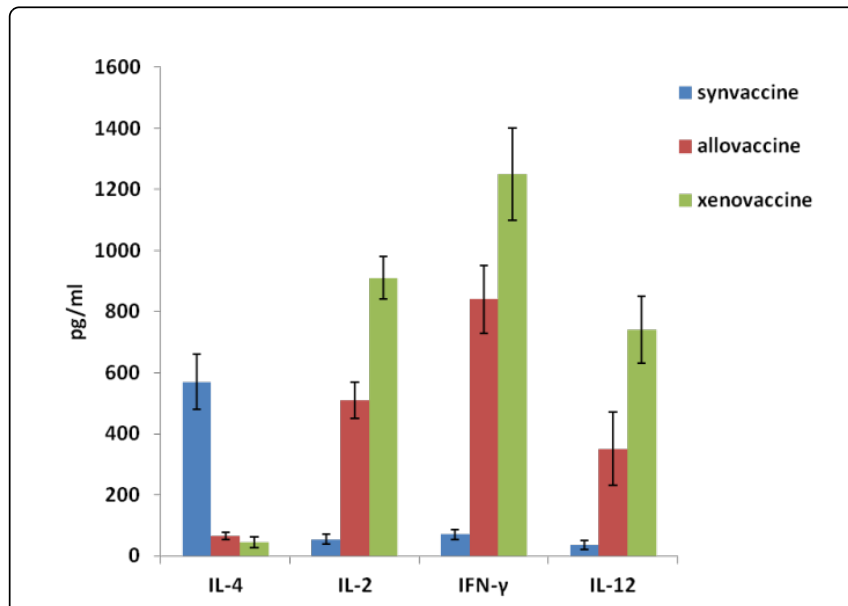

Figure 3: Cytokine response in mice immunized with various forms of vaccine when primed with whole cell lysate of macrophages infected with live $C$. neoformans. Culture supernatant of the splenocytes derived from different immunized groups was analyzed by ELISA method. The level of IL-4, IL-2, IL-12 and IFN- $\gamma$ were expressed as $\mathrm{pg} / \mathrm{ml}$. Each bar represents the mean of three determinations \pm S.D.

\section{Upregulated expression of IgG1 and IgG2a isotypes by immunizing the animals with different forms of vaccine}

We also performed IgG isotyping to examine the Th1/Th2 polarization. The sera of immunized animals were analyzed for the presence of lysate specific vaccines. As is evident from our results (Figure 4) xenovaccine was found to induce highest antibody production of both IgG1 and IgG2a isotypes. Following second immunization of all the experimental groups with the synvaccine, we found a dramatic isotype switching among various immunized animals. While animals that were immunized with the syngenic form of the vaccine were found to induce IgG1 isotype preferentially, the other two groups that were immunized with the allogenic and the xenogeneic vaccine were found to induce IgG2a isotype of antibodies. The animals that were immunized with the sham vaccine failed to induce antibody against the fungal lysate.

\section{Xenovaccines augment the expression of co-stimulatory molecules (CD80 and CD86) on lymphocyte surface}

We also carried out expression of co-stimulatory molecules (CD80 and CD86) on the surface of cultured splenocytes. As shown in Figure $5 \mathrm{~A}$, there was a substantial increase in the expression of the costimulatory molecules in the various groups of mice immunized with the various forms of vaccine. The data was most evident in case of mice 
Citation: Chauhan A, Khan N, Pooja C, Khan AA, Swaleha Z, et al. (2016) Xenogenic Gama-irradiated Pathogen Harbouring Macrophage Based Vaccine: Prophylactic Potential against Intracellular Pathogen C. neoformans. J Vaccines Vaccin 7: 316. doi: $10.4172 / 2157-7560.1000316$

Page 5 of 8

immunized with xenovaccines. The animals immunized with the xenovaccines were able to induce the expression of $39.5 \% \mathrm{CD} 80^{+}$cells followed by allovaccines $24.6 \%$ and synvaccines $10.4 \%$. The xenovaccine immunized animals induced the expression of $28.2 \%$ $\mathrm{CD}^{+} 6^{+}$cells followed by allovaccine $18.6 \%$ and synvaccine $14.5 \%$. There was no significant expression in CD80 and CD86 molecules on the surface of splenocytes in groups immunized with sham macrophages. This clearly ascertains the fact that xenovaccines were able to activate macrophages to the highest degree as compared to syngenic or for that matter allogenic vaccine. $\mathrm{CD} 4^{+} \mathrm{T}$ cells isolated from mice vaccinated with Xenovaccine exhibited a typical effector memory (CD44highCD62Llow) as well as central memory phenotype (CD44highCD62Lhigh). Other control groups including allovaccine induced central memory to some extent on three-week post challenge. The population of effector memory phenotype in synvaccine immunized group was relatively less (Figure 5C). Interestingly, $\mathrm{CD}^{+} \mathrm{T}$ cells isolated from synvaccine immunized group of animals showed effector memory (CD44highCD62Llow) phenotype. On the other hand, the (CD44highCD62Lhigh) central memory phenotype was also found to persist in animals immunized with Xenovaccine. Importantly, effector memory phenotype was significantly higher in animals immunized with xenovaccine, when compared to other groups such as Allovaccine (p, 0.01) and Synvaccine (p, 0.01), (Figure 5C). Protection studies Protection against $C$. neoformans was further confirmed by determination of fungal burden in vital organs of the vaccinated animals. As per our hypothesis vaccination with macrophages primed with pathogens peptides lead to generation of effective CTL response which subdues virulence of infection and helps in eradication of the infection. As shown in Figure 6 there was marked reduction in fungal burden in kidney and spleen of animals challenged with $C$. neoformans in xenovaccine group followed by allovaccine and synvaccine group $5^{\text {th }}$ day post challenge which decreased further $15^{\text {th }}$ day post challenge(Figures $6 \mathrm{~A}$ and $6 \mathrm{~B}$ ).

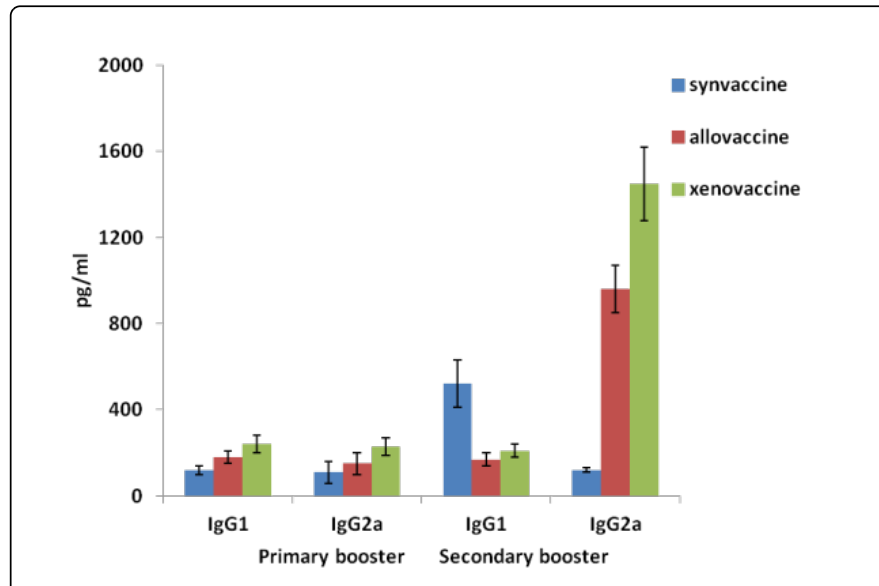

Figure 4: Analysis of IgG subtypes in mice immunized with different forms of vaccines in response to whole cell lysate of macrophages infected with live $C$. neoformans. Sera obtained from various experimental groups after each booster were assayed individually by ELISA method. The level of IgG1 and IgG2a was expressed as $\mathrm{pg} / \mathrm{ml}$. Each bar represents the mean of three determinations \pm S.D.
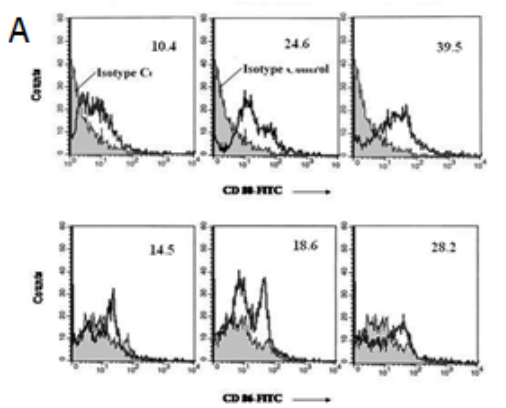

B

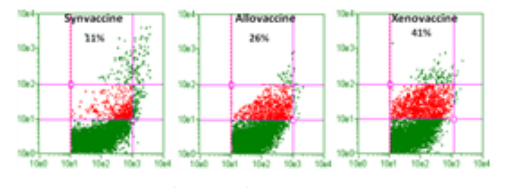

$\mathrm{CD} 4 \mathrm{FITC} \longrightarrow$

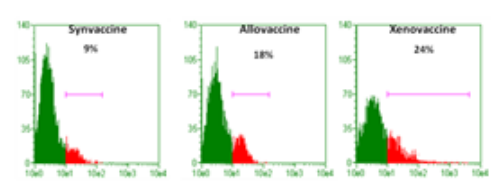

$\mathrm{CD} 8 \mathrm{PE} \longrightarrow$

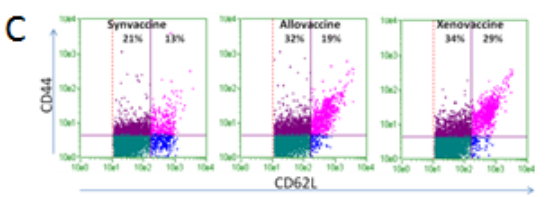

$\mathrm{CD} 4 \mathrm{CD} 44 \mathrm{CD} 62 \mathrm{~L}$

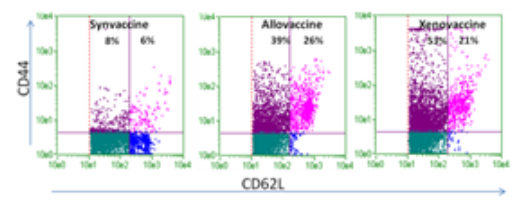

$\mathrm{CD} 8 \mathrm{CD} 44 \mathrm{CD} 62$

Figure 5: A) FACS analysis of splenocytes for the expression of co-stimulatory molecules. Co-stimulatory molecules on the surface of splenocytes were determined using FACS. The spleenocytes were stained with anti-CD80 and anti-CD86 molecules in triplicate. FITC-labelled anti-CD80 and anti-CD86 were used as the isotype control. B) Evaluation of number of cells containing surface marker CD4 ${ }^{+}$and CD8 ${ }^{+}$ present on T-cytotoxic cells in the mice immunized with the various formulation. The percentage of surface marker $\mathrm{CD} 4^{+}$and $\mathrm{CD} 8^{+}$present on $\mathrm{T}$ population of the animals immunized with Synvaccine (A); Allovaccine (B) and Xenovaccine (C) are shown. C) FACS analysis of splenocytes for the expression of memory markers. Spleenocytes cells isolated from mice vaccinated with different formulation exhibited a typical effector memory (CD44high CD62Llow) as well as central memory phenotype (CD44high CD62Lhigh).

Prophylactic potential of various macrophage based vaccine was also carried out. As shown in Figure 7 animals vaccinated with various macrophage based vaccines showed significant protection against challenge with live virulent strains of $C$. neoformans. Survival was highest in xenovaccine group (80\%) followed by allovaccine group (70\%) and synvaccine group (50\%) (Figure7). Thus, the in-house prepared xenogeneic pathogen harboring macrophages proved to be a better vaccine candidate against intracellular pathogens such as $C$. neoformans. 
Citation: Chauhan A, Khan N, Pooja C, Khan AA, Swaleha Z, et al. (2016) Xenogenic Gama-irradiated Pathogen Harbouring Macrophage Based Vaccine: Prophylactic Potential against Intracellular Pathogen C. neoformans. J Vaccines Vaccin 7: 316. doi: $10.4172 / 2157-7560.1000316$

Page 6 of 8

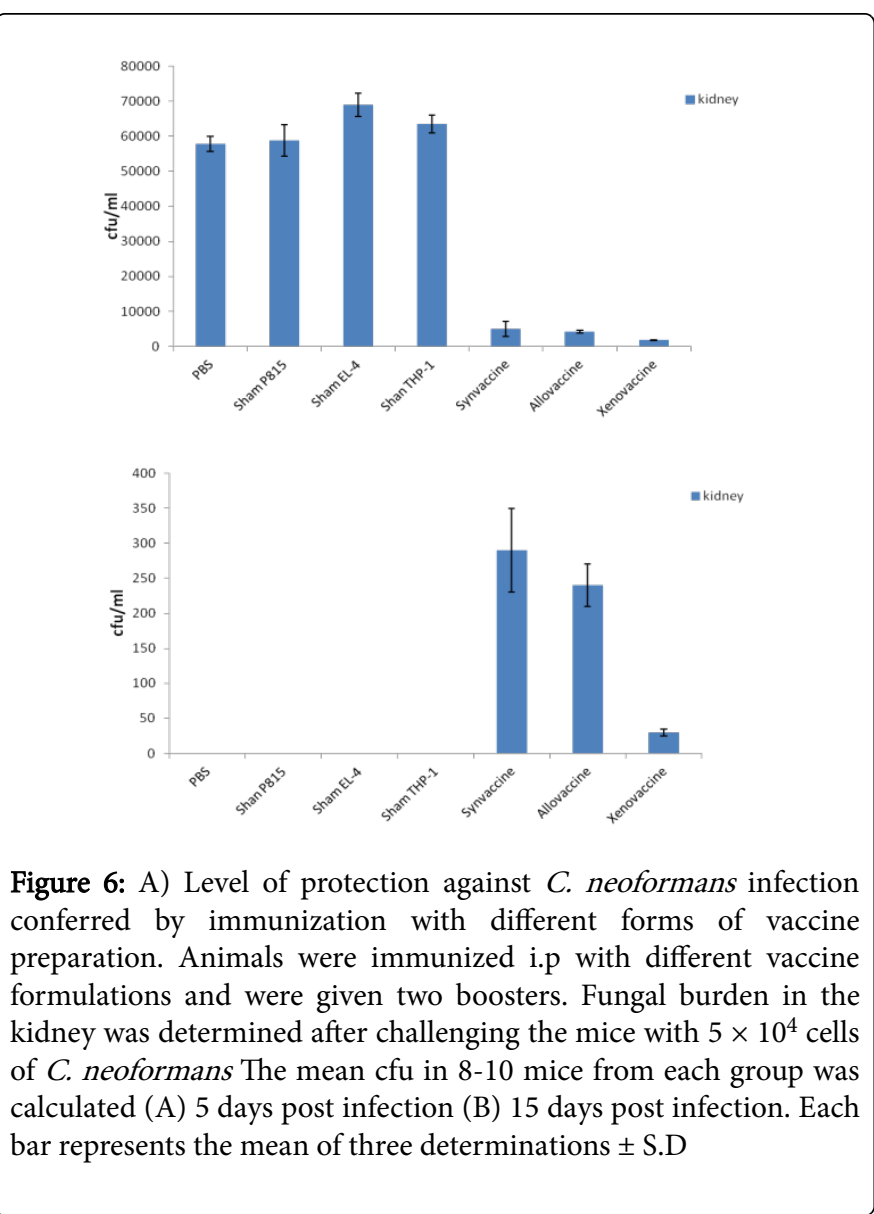

\section{Discussion}

Recent surge in the use of antifungal agents is shifting the population of fungal pathogens towards species that are intrinsically resistant to a range of antifungal agents. Systemic fungal infection occurs at a high frequency in the immunocompromised patients such as those suffering from cancer and AIDS. Patients with such debilitating conditions are increasing at an alarming rate. The need of the hour is to develop an effective vaccine against such pathogens so that antibodies and CTLs generated by such vaccines can protect the patients against such life threatening diseases.

The role of immunological response against dimorphic fungi has been a matter of concern. Several groups are of the opinion that Candida and Cryptococcus specific antibodies may be protective in experimentally disseminated candidiasis and cryptococcosis. On the contrary, various lines of evidences militate against the protective function of specific antibodies. In fact this can be attributed to the ability of the fungi to switch between unicellular yeast and filamentous forms in the infected patients [27]. Antibodies produced by the activation of B-cells are protective during early infection period, when the pathogen is present in systemic circulation as unicellular yeast. However, once it establishes itself in the host as a filamentous form, antibodies are no more significant in imparting protection. In this case the cell mediated immunity comes to the rescue. Activated CTLs can induce apoptosis in the infected cells and lead to the elimination of the pathogen [28].

\section{Survival studies}

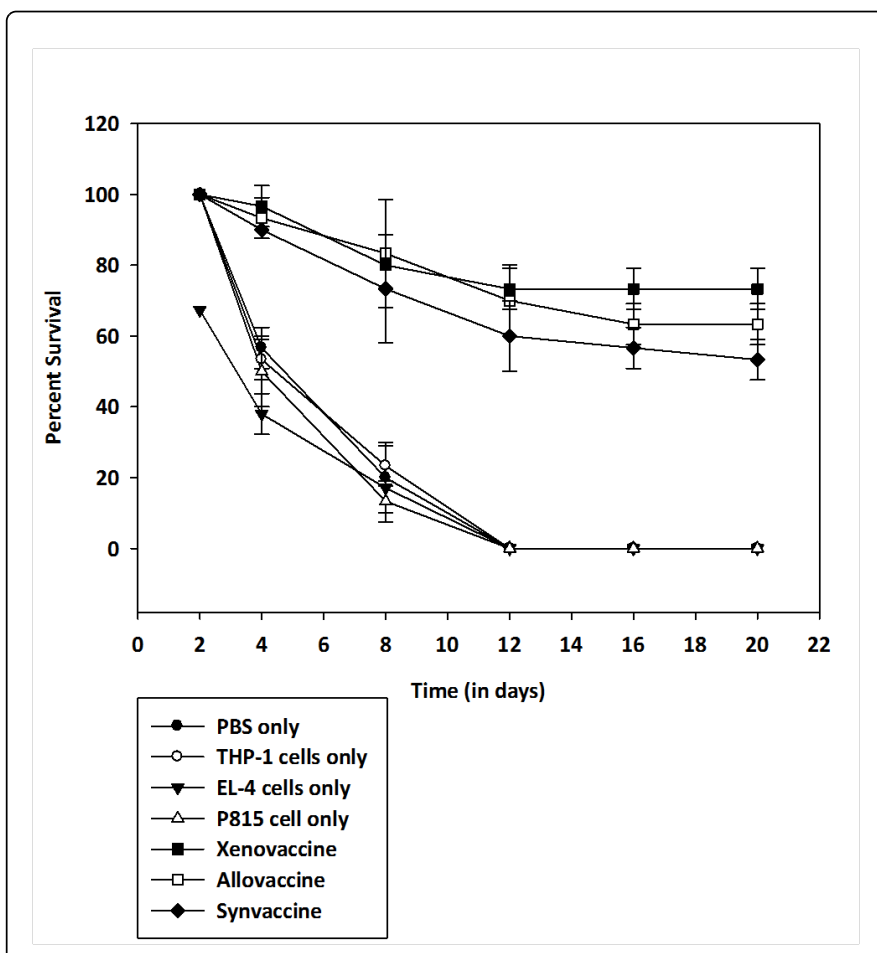

Figure 7: Percent survival of animals in various immunized groups on different days post $C$. neoformans infection. Eight to ten mice were taken in each group and the survival rate observed after infection with live $C$. neoformans. The experiments repeated three times. Each point in the graph represents the mean of three determinations \pm S.D.

It was originally thought that a cell's major histocompatibility complex (MHC) class I molecules presented peptides are derived exclusively from proteins synthesized by the cell itself. However, in some circumstances, antigens from the extracellular environment can be presented on MHC class I molecules and stimulate CD8+ T-cell immunity, a process termed cross presentation [29]. Cross presentation was originally discovered as an obscure phenomenon in transplantation immunity. However, it is now clear that it is a major mechanism by which the immune system monitors tissues and phagocytes for the presence of foreign antigen. Cross presentation is the only pathway by which the immune system can detect and respond to viral infections or mutations that exclusively occur in parenchymal cells rather than in bone marrow-derived antigen-presenting cells (APCs). Professional APCs, such as dendritic cells, are the principal cells endowed with the capacity to cross-present antigens. In this process, the APCs acquire proteins from other tissue cells through endocytic mechanisms, especially phagocytosis or macropinocytosis. The internalized antigen can then be processed through at least two different mechanisms. In one pathway, the antigen is transferred from the phagosome into the cytosol, where it is hydrolyzed by proteasomes into oligopeptides that are then transported by the transporter associated with antigen processing to MHC class I molecules in the endoplasmic reticulum or phagosomes. In a second pathway, the antigen is cleaved into peptides by endosomal proteases, particularly cathepsin S, and bound by class I molecules probably in the endocytic compartment itself. Depending on the nature of the antigen, one or 
Citation: Chauhan A, Khan N, Pooja C, Khan AA, Swaleha Z, et al. (2016) Xenogenic Gama-irradiated Pathogen Harbouring Macrophage Based Vaccine: Prophylactic Potential against Intracellular Pathogen C. neoformans. J Vaccines Vaccin 7: 316. doi: $10.4172 / 2157-7560.1000316$

Page 7 of 8

both of these pathways can contribute to cross-presentation in vivo. The outcome of cross presentation can be either tolerance or immunity. Which of these outcomes occurs is thought to depend on whether antigens are acquired by themselves alone, leading to tolerance, or with immune-stimulatory signals, leading to immunity. One source of such signals is from dying cells that release immune-stimulatory 'danger' signals that promote the generation of immunity to their cellular antigens [30]. It is this concept that prompted us to use $\gamma$ irradiated pathogen primed macrophages as vaccines against intracellular fungal pathogens. The engulfment of these apoptotic cells by dendritic cells will cause cross presentation of the antigens to the T-cells leading to activation of the host immune system.

From the Figures 1 and 2 it is quite evident that T-cell proliferation in response to whole cell lysate of macrophages infected with live $C$. neoformans is much better in response to the T- cell proliferation in response to the cytosolic fraction of $C$. neoformans. The T-cell proliferation which was measured as the rate of incorporation of $\left[\mathrm{H}^{3}\right]$ Thymidine shows the same level of response, but at a much lower concentration of about $100 \mu \mathrm{g} / \mathrm{ml}$ of whole cell lysate of macrophages infected with live $C$. neoformans. The T-cell proliferation was found to be maximum in case of mice immunized with the xenovaccine in all the cases, which is due to the fact that xenovaccine shares the greatest degree of unrelatedness.

From the cytokine profiling shown in Figures 3 it is clear that mice immunized with different forms of vaccine when primed with the whole cell lysate of macrophages infected with $C$. neoformans show an increase in the level of IFN- $\gamma$, IL-2, IL-12 whereas there is a decrease in the concentration of IL- 4 . This clearly shows that a $\mathrm{CD}^{+} \mathrm{T}$-cell mediated Th-1 response was generated. The effect of this response was found to be most significant in case of animals immunized with xenovaccines, as xenovaccines were genetically the most disparate.

The Figure 4 showing the IgG isotyping also supports the above discussed data. From the figure it is clear that following secondary booster with synvaccine there was marked increase in the levels of IgG2a as compared to IgG1.This clearly documents that it is a Th1 type of cell mediated immune response. In this case also the response in the group of mice immunized with xenovaccine was most evident, due to reasons discussed above.

The FACS data (Figure 5) showing the expression of CD80 and CD86 also shows that there is a gradual increase in the expression of the co-stimulatory molecules in the various groups of mice immunized with the various forms of vaccine. The data was most evident in case of mice immunized with xenovaccines. This clearly ascertains the fact that xenovaccines were able to activate macrophages to the highest degree as compared to syngenic or for that matter allogenic vaccine.

Although $\mathrm{CD}^{+} \mathrm{T}$ cells play crucial role in prophylactic action against $C$. neoformans, however $\mathrm{CD} 8^{+} \mathrm{T}$ cells are also equally needed for the same, especially during the chronic phase of infection. There was a substantially greater percentage of effector memory phenotype (CD44highCD62Llow) as well as central memory phenotype (CD44highCD62Lhigh) on both $\mathrm{CD}^{+}$and $\mathrm{CD}^{+} \mathrm{T}$ cells belonging to animals immunized with Xenovaccine. In general, central memory persists after rapid clearance of acute infections, and is more effective in controlling secondary infections involving intracellular pathogens. On the other hand, the effector memory was reported to be induced by chronic infections. This fact is clearly suggestive of the continued lowlevel presentation of $\mathrm{Ag}$ to both the $\mathrm{CD} 4^{+}$and $\mathrm{CD} 8^{+} \mathrm{T}$ cells by APCs at later time points and thus predicts an Ag-depot effect offered by
Xenovaccine, which in turn results in producing a balanced central and effector memory in the host.

Figures $6 \mathrm{~A}$ and $6 \mathrm{~B}$ showing the fungal load in various organs (kidney and spleen) of mice immunized with various vaccine formulations clearly depicts that the fungal load decreases considerably on the $15^{\text {th }}$ day post infection. The decrease is maximum in case of the group immunized with xenovaccine. The survival curve of the various groups of animals (Figure 7) also supports the above data.

Thus, from our present experiment we can conclude that $\gamma$ irradiated pathogen primed macrophages of different types (synvaccine, allovaccine, xenovaccine) showed greater efficacy in combating infection than the cytosolic fractions of the pathogen and amongst these types xenovaccine established itself an upper hand to all these vaccine. Thus it proved to be a better candidate for vaccine against intracellular pathogen, $C$. neoformans.

\section{Statistical analysis}

Statistical analysis performed using student's t-test. Differences were considered statistically significant with $\mathrm{P}$ value $<0.05$.

\section{Conflict of Interest}

There was no conflict among authors.

\section{Acknowledgement}

The authors thank Professor M Saleemuddin coordinator, Interdisciplinary Biotechnology Unit for providing us the institute's research facilities. We are thankful to Professor Akhtar Mahmood Director CIF, Punjab University, Chandigarh for helping us in electron microscopic studies. We are also thankful to Drs. CR Suri and JN Agrewala, IMTECH Chandigarh and Professor $\mathrm{R}$ Mahmood Department of Biochemistry, AMU for critical reviewing of the manuscript and constructive suggestions.

\section{References}

1. Mitchell TG, Perfect JR (1995) Cryptococcosis in the era of AIDS--100 years after the discovery of Cryptococcus neoformans. Clin Microbiol Rev 8: 515-548.

2. Vilchez RA, Fung J, Kusne S (2002) Cryptococcosis in organ transplant recipients: an overview. Am J Transplant 2: 575-580.

3. Krcmery V, Krupova I, Denning DW (1999) Invasive yeast infections other than Candida spp. in acute leukaemia. J Hosp Infect 41: 181-194.

4. Casadevall A, Perfect JR (1998) Cryptococcus neoformans. ASM Press, Washington, DC, USA.

5. Lui G, Lee N, Ip M, Choi KW, Tso YK, et al. (2006) Cryptococcosis in apparently immunocompetent patients. QJM 99: 143-151.

6. Perfect JR, Heitman J, Filler SG, Edwards Jr JE, Mitchell AP (2006) In: Molecular principles of fungal pathogenesis. ASM Press, Washington, DC, USA.

7. Rozenbaum R, Gonçalves AJ (1994) Clinical epidemiological study of 171 cases of cryptococcosis. Clin Infect Dis 18: 369-380.

8. Bulmer GS (1976) Lectures in medical mycology (2nd edn). University of Oklahoma Health Sciences Center, Oklahoma City, Oklahoma.

9. Kechichian TB, Shea J, Del Poeta M (2007) Depletion of Alveolar Macrophages Decreases the Dissemination of a GlucosylceramideDeficient Mutant of Cryptococcus neoformans in Immunodeficient Mice. Infect Immun 75: 4792-4798 
Citation: Chauhan A, Khan N, Pooja C, Khan AA, Swaleha Z, et al. (2016) Xenogenic Gama-irradiated Pathogen Harbouring Macrophage Based Vaccine: Prophylactic Potential against Intracellular Pathogen C. neoformans. J Vaccines Vaccin 7: 316. doi: 10.4172/2157-7560.1000316

Page 8 of 8

10. Diamond RD, Bennett JE (1973) Disseminated cryptococcosis in man: decreased lymphocyte transformation in response to Cryptococcus neoformans. J Infect Dis 127: 694-697.

11. Feldmesser M, Tucker S, Casadevall A (2001) Intracellular parasitism of macrophages by Cryptococcus neoformans. Trends Microbiol 9: 273-278.

12. Feldmesser M, Kress Y, Novikoff P, Casadevall A (2000) Cryptococcus neoformans is a facultative intracellular pathogen in murine pulmonary infection. Infect Immun 68: 4225-4237.

13. Levitz SM (2001) Cryptococcus neoformans intracellular or extracellular? Trends Microbiol 9: 417-418.

14. Chang WL, van der Heyde HC, Klein BS (1998) Flow cytometric quantitation of yeast a novel technique for use in animal model work and in vitro immunologic assays. J Immunol Methods 211: 51-63.

15. Diamond RD, Bennett JE (1973) Growth of Cryptococcus neoformans within human macrophages in vitro. Infect Immun 7: 231-236.

16. Huffnagle GB, Boyd MB, Street NE, Lipscomb MF (1998) IL-5 is required for eosinophil recruitment, crystal deposition, and mononuclear cell recruitment during a pulmonary Cryptococcus neoformans infection in genetically susceptible mice (C57BL/6). J Immunol 160: 2393-2400.

17. Levitz SM, Nong SH, Seetoo KF, Harrison TS, Speizer RA, et al. (1999) Cryptococcus neoformans resides in an acidic phagolysosome of human macrophages. Infect Immun 67: 885-890.

18. Tucker SC, Casadevall A (2002) Replication of Cryptococcus neoformans in macrophages is accompanied by phagosomal permeabilization and accumulation of vesicles containing polysaccharide in the cytoplasm. Proc Natl Acad Sci U S A 99: 3165-3170.

19. Chrétien F, Lortholary O, Kansau I, Neuville S, Gray F, et al. (2002) Pathogenesis of cerebral Cryptococcus neoformans infection after fungemia. J Infect Dis 186: 522-530.

20. Luberto C, Martinez-Mariño B, Taraskiewicz D, Bolaños B, Chitano P, et al. (2003) Identification of App1 as a regulator of phagocytosis and virulence of Cryptococcus neoformans. J Clin Invest 112: 1080-1094.
21. Alvarez M, Casadevall A (2006) Phagosome extrusion and host-cell survival after Cryptococcus neoformans phagocytosis by macrophages. Curr Biol 16: 2161-2165.

22. Ma H, Croudace JE, Lammas DA, May RC (2006) Expulsion of live pathogenic yeast by macrophages. Curr Biol 16: 2156-2160.

23. Pasare C, Medzhitov R (2004) Toll-like receptors and acquired immunity. Semin Immunol 16: 23-26.

24. Iwasaki A, Medzhitov R (2004) Toll-like receptor control of the adaptive immune responses. Nat Immunol 5: 987-995.

25. Hemmi H, Akira S (2005) TLR signalling and the function of dendritic cells. Chem Immunol Allergy 86: 120-135.

26. Bianchi ME (2007) DAMPs, PAMPs and alarmins: all we need to know about danger. J Leukoc Biol 81: 1-5.

27. Han Y, Cutler JE (1995) Antibody response that protects against disseminated candidiasis. Infect Immun 63: 2714-2719.

28. Chauhan A, Swaleha Z, Ahmad N, Farazuddin M, Vasco A, et al. (2011) Escheriosome mediated cytosolic delivery of Candida albicans cytosolic proteins induces enhanced cytotoxic $\mathrm{T}$ lymphocyte response and protective immunity. Vaccine 29: 5424-5433.

29. Chauhan A, Swaleha Z, Ahmad N, Farazuddin M, Vasco A, et al. (2011) Escheriosome mediated cytosolic delivery of Candida albicans cytosolic proteins induces enhanced cytotoxic $\mathrm{T}$ lymphocyte response and protective immunity. Vaccine 29: 5424-5433.

30. Heath WR, Carbone FR (2001) Cross-presentation in viral immunity and self-tolerance. Nat Rev Immunol 1: 126-134.

31. Rock KL, Shen L (2005) Cross-presentation: underlying mechanisms and role in immune surveillance. Immunol Rev 207: 166-183. 